\title{
UMA PERSPECTIVA COMPUTACIONAL SOBRE CATÁLISE ENZIMÁTICA
}

\author{
Guilherme M. Arantes* \\ Instituto de Química, Universidade de São Paulo, Av. Lineu Prestes 748, 05508-900 São Paulo - SP, Brasil
}

Recebido em 24/11/06; aceito em 18/5/07; publicado na web em 19/12/07

\begin{abstract}
A COMPUTATIONAL PERSPECTIVE ON ENZYMATIC CATALYSIS. Enzymes are extremely efficient catalysts. Here, part of the mechanisms proposed to explain this catalytic power will be compared to quantitative experimental results and computer simulations. Influence of the enzymatic environment over species along the reaction coordinate will be analysed. Concepts of transition state stabilisation and reactant destabilisation will be confronted. Divided site model and near-attack conformation hypotheses will also be discussed. Molecular interactions such as covalent catalysis, general acid-base catalysis, electrostatics, entropic effects, steric hindrance, quantum and dynamical effects will also be analysed as sources of catalysis. Reaction mechanisms, in particular that catalysed by protein tyrosine phosphatases, illustrate the concepts.
\end{abstract}

Keywords: enzymatic catalysis; computer simulation; reaction mechanism.

\section{INTRODUÇÃO}

Enzimas são catalisadores de extraordinária eficiência. Os aumentos de velocidade de reações alcançados por enzimas podem chegar a vinte ordens de magnitude ${ }^{1}$ ! Por outro lado, enzimas possuem uma grande especificidade pelos substratos, sua atividade é controlável e totalmente seletiva.

Sob uma perspectiva teórica, a sugestão de Fischer $^{2}$, conhecida como a hipótese da "chave e fechadura", foi a primeira proposta para explicar o poder catalítico das enzimas. Com o advento da teoria do estado de transição ${ }^{3}$ nos anos 1930 , Pauling ${ }^{4}$ propôs que esta espécie seria preferencialmente ligada pelo sítio ativo enzimático. Já em 1969, Jencks ${ }^{5}$ escreveu que "o estudo dos mecanismos moleculares de catálise enzimática é necessariamente empírico e qualitativo". No entanto, nos últimos 30 anos, simulações computacionais que permitem determinações quantitativas de propriedades termodinâmicas têm alterado este panorama, apontando e quantificando os mecanismos catalíticos empregados por enzimas.

Cabem aqui duas definições. O termo "mecanismo catalítico" é usado para descrever as forças ou interações microscópicas utilizadas pelas enzimas para amplificar a velocidade de reações. Já "mecanismo de reação" é a seqüência de transformações (quebra e formação de ligações químicas) e mudanças de estrutura do complexo enzimático observadas ao longo do progresso da reação.

Diversos mecanismos catalíticos já foram propostos para explicar as acelerações enzimáticas em nível microscópico. Por exemplo, Menger contabilizou 21 teorias sobre catálise enzimática ${ }^{6}$. Este número é elevado em conseqüência de diferentes interpretações semânticas e imprecisas definições de quantidades termodinâmicas nas teorias propostas, e também porque a maior parte destas teorias não foi (ou não pode ser) testada quantitativamente. Portanto, há muita controvérsia sobre a importância de cada um dos diferentes mecanismos e teorias propostos para explicar o poder catalítico das enzimas ${ }^{7-9}$.

Sem dúvida, cada enzima possui sua própria "receita" para catálise, em que uma combinação das interações propostas pode estar atuando. O principal objetivo deste texto é analisar e

*e-mail: garantes@iq.usp.br quantificar a contribuição de cada uma destas interações para o aumento da velocidade de reações no ambiente enzimático. Inicialmente apresentaremos o modelo básico e suas equações macroscópicas para a atividade enzimática, e a definição de reação de referência em solução aquosa, que deve ser usada na comparação com a reação enzimática. Em seguida, discutiremos qual espécie ao longo da coordenada de reação sofre influência determinante do ambiente enzimático. A hipótese de desestabilização do estado reagente (complexo enzima-substrato ou complexo de Michaelis) será confrontada com a hipótese de estabilização do estado de transição (TS ${ }^{3}$. Propostas relacionadas como as conformações próximas ao ataque ${ }^{10}$ e do sítio dividido ${ }^{6}$ também serão analisadas.

As interações moleculares usadas para explicar os mecanismos catalíticos, incluindo catálise covalente, catálise ácido-base geral, interação eletrostática, efeitos entrópicos, impedimento estérico e, efeitos quânticos e dinâmicos serão discutidas. Esta lista de interações pode ser incompleta, dada a limitação de tamanho para este texto, e parcial, pois reflete as propostas que foram testadas e quantificadas por simulações computacionais. Mecanismos de reação de algumas enzimas, em particular as proteínas tirosinafosfatases, serão usados para ilustrar os conceitos discutidos ${ }^{11}$.

\section{DESCRIÇÃO MACROSCÓPICA}

As Equações de Michaelis-Mentem ${ }^{12,13}$ são o modelo básico usado para descrever cinética enzimática para um único substrato, $S$ :

$$
\begin{aligned}
& \mathrm{E}+\mathrm{S} \underset{k_{-1}}{\stackrel{k_{1}}{\rightleftharpoons}} \mathrm{E} \cdot \mathrm{S} \stackrel{k_{c a t}}{\longrightarrow} \mathrm{E}+\mathrm{P} \\
& K_{S}=\frac{[\mathrm{E}][\mathrm{S}]}{[\mathrm{E} \cdot \mathrm{S}]}=\frac{k_{-1}}{k_{1}} \\
& K_{M}=\frac{k_{-1}+k_{\text {cat }}}{k_{1}}
\end{aligned}
$$

onde $\mathrm{E}$ denota enzima, $\mathrm{P}$ é o produto, $K_{\mathrm{S}}$ é a constante de equilíbrio para dissociação do complexo E.S, $k_{\text {cat }}$ é a constante de velocidade de reação observada e $K_{M}$ é a constante de Michaelis. Na maioria dos casos, $k_{-I}>k_{\text {cat }}$, portanto, $K_{S} \approx K_{M}$. Neste modelo, a velocida- 
de inicial de formação do produto, $\mathrm{v}=k_{\text {cat }}$ [E.S], também pode ser escrita como:

$\mathrm{v}=\frac{k_{\text {cat }}[\mathrm{E}]_{\mathrm{T}}[\mathrm{S}]}{K_{M}+[\mathrm{S}]}$

onde definimos a concentração total de enzima, $[\mathrm{E}]_{\mathrm{T}}=[\mathrm{E}]+[\mathrm{E} . \mathrm{S}]$. Equações semelhantes também são válidas para sistemas mais complexos como, por exemplo, na presença de dois ou mais substratos diferentes. Nestes casos, a definição da constante $K_{S}$ é alterada.

Considerando este modelo, existem três maneiras da evolução maximizar a constante de velocidade de catálise aparente, definida como $k_{c a t} / K_{M}$. Alteração somente de $K_{S}$ para um determinado substrato pode amplificar a velocidade de catálise aparente pelo aumento da [E.S], além de modificar a seletividade por este substrato. Um dos possíveis mecanismos empregados neste caso é o encaminhamento, em que o volume livre para difusão do substrato é reduzido ou por mudanças estruturais na enzima (como em complexos enzimáticos multi-unidades) ou por interações eletrostáticas que guiam o substrato para o sítio ativo ${ }^{14}$. A velocidade de catálise também pode ser amplificada pelo aumento da $k_{\text {cat }}$ sem alteração da seletividade pelo substrato, ou seja, apenas aumentando a velocidade da etapa de transformação química na enzima. Finalmente, a velocidade de catálise pode ser aumentada pela modificação simultânea de $k_{c a t}$ e $K_{S}$. Não discutiremos aqui processos que alterem apenas a associação entre enzima e substrato $\left(K_{S}\right)$. Este texto focaliza os processos que aumentam a velocidade de catálise principalmente pelo aumento de $k_{c a t}$.

\section{REAÇÃO DE REFERÊNCIA}

Para identificação das fontes de aceleração enzimática, a reação catalisada deve ser comparada com uma reação de referência em solução aquosa sem catálise. Caso a reação enzimática e a reação observada em solução ocorrem segundo o mesmo mecanismo, ou seja, possuam um estado de transição semelhante, o seguinte ciclo termodinâmico pode ser usado para comparação:

$$
\begin{aligned}
& \mathrm{E}+\mathrm{S} \quad \stackrel{k_{\text {non }}}{\longrightarrow} \quad \mathrm{E}+\mathrm{S}^{\ddagger} \longrightarrow \mathrm{E}+\mathrm{P} \\
& K=1 \downarrow \\
& \downarrow K_{T S} \\
& \mathrm{E}+\mathrm{S} \stackrel{K_{S}}{\rightleftharpoons} \mathrm{E} \cdot \mathrm{S} \stackrel{k_{\text {cat }}}{\longrightarrow} \mathrm{E} \cdot \mathrm{S}^{\ddagger} \longrightarrow \mathrm{E}+\mathrm{P}
\end{aligned}
$$

A velocidade de reação na enzima será maior que a reação não catalisada em solução se $k_{c a t} / K_{S}>k_{n o n}$. Neste caso, a afinidade da enzima pelo TS ou complexo ativado, $\mathrm{S}^{\ddagger}$, é $K_{T S}=\left(k_{\text {cat }} / K_{S}\right) / k_{n o n}>0$, ou seja, o complexo ativado é mais estável quando ligado à enzima que quando em solução.

No entanto, o mecanismo de reação atuante no sítio enzimático pode ser diferente do mecanismo de reação observado em solução aquosa na ausência do catalisador. Por exemplo, a hidrólise de ésteres de fosfato em solução aquosa ocorre diretamente num ataque nucleofílico por uma molécula de água. Porém, a mesma reação catalisada pelas proteínas tirosina-fosfatases (PTPs) ocorre em duas etapas: uma tiólise do éster de fosfato, seguida de uma hidrólise do intermediário tiofosforilado (Figura 1) ${ }^{15,16}$.

Nestes casos, o mecanismo de reação na enzima não deve ser

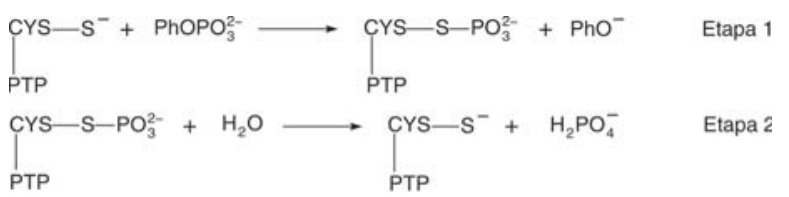

Figura 1. Esquema da reação de hidrólise catalisada pelas proteínas tirosinafosfatases (PTP). Ph indica um grupo fenil e CYS, o resíduo de cisteina diretamente comparado com o mecanismo observado em solução via um ciclo termodinâmico como o da Equação 5. A análise do efeito enzimático deve ser feita em comparação com uma reação de referência em solução aquosa (caracterizada por $k_{\text {non }}$ ), constituída pelos mesmos grupos reativos ( $\mathrm{R}$ e S na Figura 2) e o mesmo mecanismo de reação na enzima, mas solvatados por água. (Figura 2) ${ }^{9,17}$. Simulações computacionais podem ser usadas para calcular o perfil energético das reações de referência que são inacessíveis experimentalmente ${ }^{18-20}$.

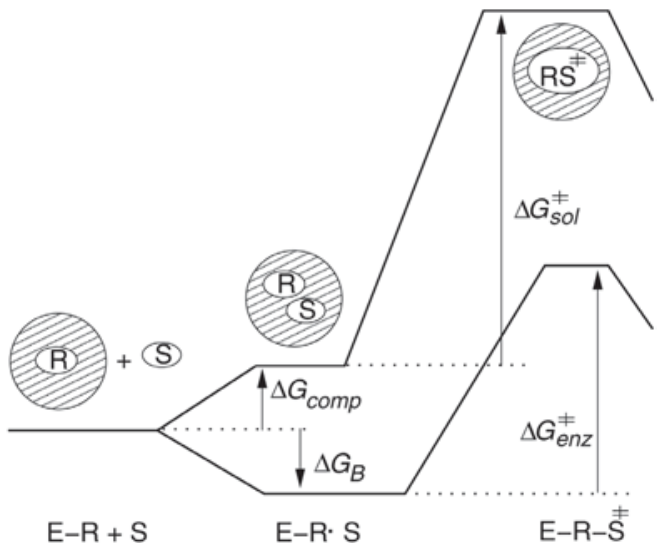

Figura 2. Esquema do perfil energético de uma reação enzimática e sua referência em solução. $\Delta G_{B}, \Delta G_{\text {comp }}, \Delta G_{\text {enz }}^{\ddagger}$ e $\Delta G_{\text {sol }}^{\ddagger}$ são, respectivamente, a energia livre de formação do complexo entre a enzima $E$ - $R$ e o substrato $S$, de complexação entre os reagentes $R$ e $S$ em solução, de ativação da reação no ambiente enzimático e de ativação da reação no complexo de encontro R.S dos reagentes em solução. A região com linhas diagonais indica o solvente aquoso

\section{ESPÉCIE CATALISADA}

\section{Estabilização do TS ou desestabilização do reagente?}

A hipótese da "chave e fechadura" proposta inicialmente por Fischer para racionalizar o poder catalítico das enzimas foi estendida pela proposta de Haldane $e^{2}$ em que o substrato não "encaixa" exatamente na enzima, mas sofre uma distorção após a formação do complexo E.S, e pela proposta de Pauling 4 , em que a enzima se liga mais fortemente ao TS que ao substrato.

A hipótese de Pauling apóia-se no conceito de estado de transição ${ }^{3}$ e diz que este é mais estabilizado no sítio ativo da enzima em relação a mesma espécie numa reação de referência em solução aquosa. Esta hipótese é amplamente aceita como principal fonte de catálise e parece válida em todas enzimas já analisadas quantitativamente ${ }^{2,10,18,19,21,22}$.

Centenas de estruturas tridimensionais determinadas para enzimas complexadas a análogos de TS apóiam a noção de complementaridade entre as estruturas do sítio ativo e do TS. Estes complexos são de grande utilidade prática no desenho de drogas que funcionam como inibidores enzimáticos competitivos ${ }^{13}$. No entanto, comprovar a hipótese de Pauling por experimentos não é diretamente possível, já que um TS é um objeto transiente. Simulações computacionais de reações enzimáticas mostram repetidamente $8,21-24$ que a interação eletrostática entre o ambiente enzimático e o TS é a maior responsável pela diminuição de $\Delta \mathrm{G}_{\mathrm{enz}}^{*}$ em relação a $\Delta \mathrm{G}_{\text {sol }}^{\ddagger}$ (Figura 2), demonstrando que o TS é a principal espécie que sofre catálise ao longo da coordenada de reação na enzima.

A afirmação de "maior ligação ou afinidade da enzima pelo TS" é por vezes interpretada literalmente, como se o TS fosse atin- 
gido em solução e, depois, ligado e estabilizado pela enzima. Esta interpretação é equivocada porque o TS tem um tempo de vida muito pequeno em solução, da ordem de $10^{-15} \mathrm{~s}$ e, portanto, não existe por um tempo suficiente para que difusão e ligação à enzima ocorram. Na interpretação correta, a enzima complexa o substrato no estado fundamental e a ativação ocorre a partir deste complexo. O TS formado possui melhores contatos com a enzima que o substrato, maximizando a estabilização apenas quando o complexo é ativado. Assim, o TS tem maior estabilidade no sítio ativo que em solução.

A proposta de Haldane equivale à desestabilização do estado reagente em relação à mesma espécie livre em solução. A desestabilização contribui para amplificar a velocidade da reação enzimática ao reduzir a barreira de ativação $\left(\Delta \mathrm{G}_{\mathrm{enz}}^{\ddagger}\right)$. No perfil de energia livre de ligação e reação representado pela curva A na Figura $3, \Delta \mathrm{G}_{\mathrm{B}}$ indica a energia livre de ligação do substrato intrínseca, ou seja, sem nenhuma desestabilização do estado reagente. Uma alteração estrutural da proteína anterior à ligação do substrato, por exemplo, em conseqüência da ligação de um regulador alostérico ou de uma mutação no sítio ativo, pode resultar em aumento da $K_{M}$ (perfil B, Figura 3). Uma alteração estrutural expressiva resultaria em grande desestabilização do complexo E.S e $K_{M}>1$ (perfil C, Figura 3). A desestabilização também pode ser conseqüência de uma mudança estrutural na enzima ${ }^{5}$ após a formação de E.S, gerando o complexo E.S' (perfil D, Figura 3).

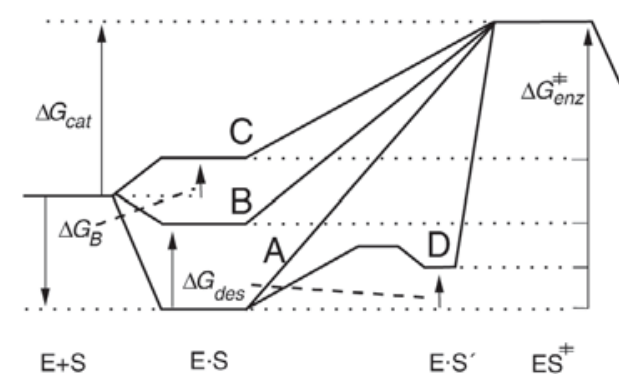

Figura 3. Esquema do perfil de energia livre de reações enzimáticas para complexos E.S com diferentes estabilidades. $\Delta G_{\mathrm{B}}, \Delta G_{\mathrm{des}}, \Delta G_{\text {enz }}^{\ddagger}$ e $\Delta G_{\text {cat }}$ são, respectivamente, a energia livre de formação do complexo E.S, de desestabilização de E.S, de ativação na enzima $\left(\Delta G_{\text {enz }}^{\ddagger}=-\mathrm{RT} \ln \left[\mathrm{k}_{\mathrm{cat}} / \mathrm{A}\right]\right.$, onde A é o fator préexponencial) e de ativação aparente $\left(\Delta G_{\text {cat }}=-\mathrm{RT} \ln \left[\left(\mathrm{k}_{\text {cat }} / \mathrm{A}\right) / \mathrm{K}_{\mathrm{M}}\right]\right)$

Jencks propôs que a energia de ligação do substrato observada nos processos representados pelos perfis B e D é $\Delta G_{B}-\Delta G_{\text {des }}$, ou seja, a diferença entre a energia de ligação intrínseca e a energia usada para desestabilizar o substrato. A desestabilização não (ou pouco) altera a energia do $\mathrm{TS}^{5}$ e $\Delta \mathrm{G}_{\text {des }}$ seria usado como fonte de catálise, reduzindo a barreira para reação na enzima. Assim, a energia de ativação na enzima é modificada para cada perfil e $\Delta \mathrm{G}_{\mathrm{enz}}^{\ddagger}(\mathrm{A})$ $>\Delta \mathrm{G}_{\mathrm{enz}}^{\ddagger}(\mathrm{D})>\Delta \mathrm{G}_{\mathrm{enz}}^{\ddagger}(\mathrm{B})>\Delta \mathrm{G}_{\mathrm{enz}}^{\ddagger}(\mathrm{C})$ (Figura 3). Esta proposta implica que enzimas têm alta afinidade intrínseca $\left(\Delta \mathrm{G}_{\mathrm{B}}\right)$ pelo substrato.

No entanto, a importância da desestabilização do substrato para catálise deve ser limitada, já que o aumento da energia do complexo E.S acima da energia de E+S (perfil C, Figura 3) não é catalítico. A velocidade máxima de uma reação reflete a diferença entre as energias livres do ponto mais alto $\left(\mathrm{ES}^{\ddagger}\right)$ e do mais baixo $(\mathrm{E}+\mathrm{S}$, no caso do perfil C) ao longo da coordenada de reação. A quantidade de energia livre disponível para catálise pela desestabilização do reagente $\left(\Delta \mathrm{G}_{\mathrm{des}}\right)$ também é pequena em comparação com a diferença entre as barreiras da reação catalisada e em solução $\left(\Delta \mathrm{G}_{\text {sol }}^{\ddagger}\right.$ $\Delta \mathrm{G}_{\text {enz }}^{\ddagger}$, Figura 2$)^{17}$.

Nenhum experimento quantificou diretamente o efeito de desestabilização para reações no sítio enzimático, mas Jencks e
Menger defendem esta proposta baseados principalmente na interpretação da reatividade de compostos orgânicos em solução $0^{5,25}$.

A análise do efeito da evolução separadamente sobre $k_{\text {cat }}$ e $K_{M}$ de diversas enzimas dentro do modelo de Michaelis-Mentem (Equação 1) com a relação $k_{\text {cal }} / K_{M}$ fixada indica que enzimas evoluíram para ligar o TS fortemente (baixo $\Delta \mathrm{G}_{\text {enz }}^{+}$ou alto $\left.k_{\text {cat }}\right)^{12}$ e os substratos fracamente (alto $K_{M}$ ). Esta conclusão está em desacordo com a proposta de Jencks (vide supra). A desestabilização do complexo E.S (perfis B e $\mathrm{D}$, Figura 3) não muda $\Delta \mathrm{G}_{\text {cat }}=-R T \ln \left[\left(k_{\text {cat }} / A\right) / K_{M}\right]$, portanto não é claro como esta proposta pode ser usada pela evolução para variar ou maximizar a velocidade de catálise aparente $\left(k_{\text {cat }} / K_{M}\right)^{17}$.

Enzimas mutantes cujo $\Delta \mathrm{G}_{\text {cat }}$ é significativamente diferente da enzima selvagem podem ser divididas em três classes: mutantes que sofrem alteração da energia do TS, resultando em diminuição apenas de $k_{\text {cat }}$ e manutenção de $K_{M}{ }^{26}$ (ou seja, $\Delta \mathrm{G}_{\text {enz }}^{\ddagger}$ é aumentado, pois o TS é desestabilizado); mutantes que sofrem modificação de um sítio de ligação distante dos grupos reativos do substrato, resultando em aumento do $K_{M}$, mas mantendo o valor de $k_{\text {cat }}$ (ou seja, o TS e o complexo E.S têm suas energias aumentadas pela mesma quantidade, logo, $\Delta \mathrm{G}_{\text {enz }}^{\ddagger}$ não muda) $)^{17}$. Não foram encontrados ${ }^{27}$ mutantes em que ambos $K_{M}$ e $k_{\text {cat }}$ seriam modificados (ou seja, $\Delta \mathrm{G}_{\text {enz }}^{\ddagger}$ e $\Delta \mathrm{G}_{\mathrm{B}}$ apresentariam aumentos da mesma magnitude). Este seria o resultado esperado para uma mutação que anule ou diminua a capacidade de desestabilização do substrato.

A desestabilização dos reagentes é freqüentemente associada à seleção pelo sítio ativo de uma conformação do substrato instável em relação à conformação mais populada em solução aquosa. A corismato mutase ${ }^{28} \mathrm{e}$ a lisozima são dois exemplos em que o substrato ligado à enzima é forçado a adotar uma conformação diferente daquela mais estável em solução aquosa. A diferença de energia livre entre os confôrmeros pode chegar a $5 \mathrm{kcal} / \mathrm{mol}$, mas esta energia não é necessariamente usada na diminuição de $\Delta \mathrm{G}^{\ddagger}{ }_{\text {enz }}{ }^{18}$. A seleção de conformações pela enzima está relacionada ao conceito de conformações próximas ao ataque, discutido na próxima seção.

\section{Conformação próxima ao ataque}

Bruice $^{29}$ introduziu o conceito de conformação próxima ao ataque (NAC), definido como a configuração estrutural que os reagentes precisam assumir para chegar ao TS. A análise conformacional de uma série de reações intramoleculares de ciclização de ácidos dicarboxílicos indicou que a fração molar dos reagentes em NACs (definidas de acordo com critérios geométricos como distância e ângulo da ligação em formação) era diretamente proporcional à velocidade da ciclização intramolecular e formação de anidrido (Figura 4) ${ }^{29}$. A distribuição de conformações dos substratos complexados aos sítios ativos em algumas reações enzimáticas que não envolvem a formação de intermediários covalentes (por exemplo, o rearranjo de corismato para perfenato, catalisado pela enzima corismato mutase) indicou que a proporção de NACs no sítio ativo enzimático era maior que na reação de referência em solução ${ }^{10}$.

No entanto, uma NAC não é uma espécie termodinamicamente estável e, portanto, sua definição não é única e depende dos critérios geométricos escolhidos. Assim, a presença de NACs não pode

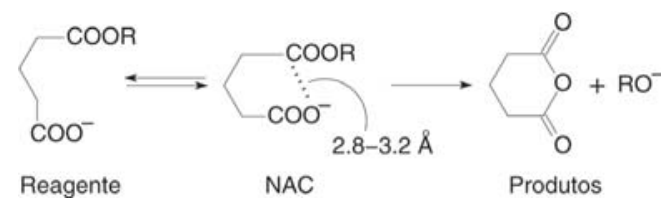

Figura 4. Esquema da reação de ciclização intramolecular passando por uma conformação próxima ao ataque (NAC), definida pela distância de 2,8 a 3,2 A entre o oxigênio nucleofílico e o carbono esterificado 
ser medida experimentalmente e sua contribuição energética para catálise é difícil de ser avaliada com precisão. Estimativas computacionais sugerem que contribuições entre 1 a $3 \mathrm{kcal} / \mathrm{mol}$ estão disponíveis para catálise através da estabilização ou seleção de NACs por enzimas, em relação à população normal de NACs observada em solução aquosa ${ }^{7,30}$.

Também inspirado pela idéia de controle estéreo-populacional em reações intramoleculares, Menger propôs sua hipótese espaçotemporal, postulando que a "velocidade da reação entre os grupos $\mathrm{X}$ e $\mathrm{Y}$ é proporcional ao tempo que $\mathrm{X}$ e $\mathrm{Y}$ residem a uma distância crítica” ${ }^{25}$. Esta hipótese é equivalente ao aumento da fração molar de NACs.

\section{Modelo do sítio dividido}

Menger também propôs uma função catalítica para o complexo E.S ${ }^{6}$. No seu modelo de sítio dividido, a interação entre o substrato e a enzima pode ser dividida em sítios ou regiões de ligação (lig) e sítios ou regiões de reação (reac). A energia livre de cada espécie é descrita pela soma das energias de cada região, $\Delta \mathrm{G}=\Delta \mathrm{G}($ lig $)+\Delta \mathrm{G}($ reac $)$. As seguintes hipóteses estão no cerne do modelo:

1. a energia de formação do complexo E.S proveniente da região ligante, $\Delta \mathrm{G}_{\mathrm{B}}$ (lig), é conservada quando o TS é alcançado, já o $\Delta \mathrm{G}_{\mathrm{B}}$ (reac) não é conservado no TS, porque a estrutura molecular nesta região é modificada;

2. as forças atuantes são sempre estabilizantes (atrativas) na região de ligação, e desestabilizantes na região reativa.

Nesta proposta, a desestabilização da parte reativa é compensada pela estabilização na região ligante. Assim, a energia de ligação total $\left(\Delta \mathrm{G}_{\mathrm{B}}\right)$ é maior que num complexo E.S com apenas uma região (reativa) desestabilizada (como os exemplos da Figura 3), e a barreira de ativação para reação é reduzida. Este modelo é semelhante à proposta de ligação uniforme feita por Alberty e Knowles ${ }^{31}$.

No entanto, o ganho em energia livre neste modelo é limitado pela diferença entre a estabilização da região ligante e a desestabilização da região reativa. Estimativas computacionais ${ }^{17}$ e medidas cinéticas para catálise de substratos com diferentes regiões ligantes mas com a mesma região reativa ${ }^{12}$ sugerem que aumentos de velocidade de apenas três ordens de magnitude podem ser obtidos pelo modelo de sítio dividido.

Por exemplo, este modelo pode explicar porque enzimas CDC25 da família das PTPs desfosforilam o substrato natural (a proteína CDK2) $10^{3}$ vezes mais rápido que substratos artificiais que possuem apenas uma região reativa e nenhuma região de ligação ${ }^{32}$.

\section{Interações e mecanismos catalíticos microscópicos}

Nesta seção, revisaremos possíveis forças e interações microscópicas que podem explicar como enzimas estabilizam o TS e aumentam a velocidade das reações catalisadas. Existe uma dificuldade intrínseca em particionar estas contribuições energéticas, porque muitas delas não são aditivas e independentes ${ }^{33}$. Por exemplo, experimentos de mutação sítio-dirigida podem avaliar a contribuição de um determinado resíduo para abaixamento da energia de ativação. No entanto, estes experimentos são sempre cooperativos, pois alteram uma série de interações, como eletrostática, impedimento estérico, dinâmica, liberdade configuracional, entre outras. Simulações computacionais são bastante poderosas para lidar com esta limitação, pois permitem que as contribuições sejam separadas e avaliadas independentemente.

Cabe aqui uma explicação sobre as contribuições discutidas a seguir e sua relação com os resultados obtidos em uma simulação. A maioria das simulações computacionais de reações enzimáticas discutidas aqui são obtidas por potenciais híbridos de mecânica quântica e mecânica molecular ${ }^{24,28}$.

Nestas simulações, a parte de mecânica quântica descreve a quebra e a formação de ligações químicas dos grupos reativos (átomos do substrato e do sítio ativo que participam da reação química) e, portanto, descreve as contribuições discutidas nas seções "Catálise covalente" e "Catálise ácido-base geral".

A parte de mecânica molecular é responsável pela descrição das forças intermoleculares, como as forças eletrostáticas e de van der Waals, e das interações ligantes, como estiramento de ligações e torções de ângulos diedrais. As contribuições da "Interação eletrostática" estão diretamente ligadas à força eletrostática presente nesta parte do potencial. Da mesma forma, "Tensão e impedimento estérico" são descritos pelas interações ligantes e de van der Waals (ver abaixo). Contribuições termodinâmicas para catálise, como descrito na seção "Efeitos entrópicos", são obtidas através da amostragem do espaço configuracional disponível ao sistema enzimático durante a simulação ${ }^{18,22}$. Finalmente, "Efeitos quânticos e dinâmicos" são observados numa simulação ou através de correções à dinâmica clássica, ou explicitamente se a dinâmica da parte reativa for tratada quanto-mecanicamente ${ }^{8}$.

\section{Catálise covalente}

Catálise covalente pode ser descrita como uma modificação química transiente na enzima que ativa o substrato ou transfere um grupo reativo do substrato para outro aceptor. Para a catálise covalente ser efetiva, as seguintes condições devem ser atingidas: o catalisador deve ter uma maior reatividade frente ao substrato que o aceptor final; o intermediário formado entre o catalisador e o substrato deve ser mais reativo que o substrato; o intermediário deve ser termodinamicamente instável (maior energia livre) em relação ao produto final, de maneira que o intermediário não acumule.

Catalisadores como proteases, estearases, descarboxilases, fosfatases (incluindo as PTPs), entre outras enzimas, formam intermediários covalentes e parecem seguir as condições acima. Por exemplo, fosfatases que utilizam um resíduo de cisteína para ataque nucleofílico sobre fósforo formam um intermediário tiofosforilado $^{15}$ (Figura 1). A energia de ativação para alcoólise ${ }^{34}$ ou hidrólise ${ }^{35}$ de tioésteres de fosfato (quebra da ligação P-S) é 6 e 10 $\mathrm{kcal} / \mathrm{mol}$ mais baixa que a respectiva reação de oxiésteres de fosfato (quebra da ligação P-O). Assim, a vantagem energética obtida pela catálise covalente é desta magnitude $(5-10 \mathrm{kcal} / \mathrm{mol})$.

Houk propôs recentemente ${ }^{36}$ que a catálise covalente é um mecanismo fundamental para todas enzimas de alta capacidade catalítica [com $\left(k_{\text {cat }} / K_{M}\right) / k_{\text {non }}>10^{11}$ ]. Contudo, este argumento pode ser refutado já que algumas das enzimas de maior capacidade catalítica não apresentam intermediários covalentes ${ }^{7}$.

A formação de intermediários resulta na divisão do processo total em diversas etapas ou reações ${ }^{37}$, portanto, o mecanismo de reação na enzima pode ser diferente do mecanismo de reação observado em solução. A análise do mecanismo catalítico deve ser feita entre cada etapa e a respectiva reação de referência não catalisada em solução (ver seção Reação de referência).

\section{Catálise ácido-base geral}

A catálise ácido-base geral, ou seja, doação (ou acepção) de $\mathrm{H}^{+}$ por um grupo enzimático que funciona como um ácido (ou uma base), é uma das etapas envolvidas em diversas reações bioquímicas. A transferência pode ocorrer de três formas: um pré-equilíbrio rápido e anterior à etapa limitante da velocidade de reação; simul- 
taneamente à reação ou, constituir a etapa limitante (por exemplo, na transferência de $\mathrm{H}^{+}$de carbonos alifáticos) $)^{5}$. No primeiro caso, as barreiras intrínsecas de transferência de $\mathrm{H}^{+}$são pequenas. Porém, a transferência pode formar intermediários de maior energia livre e, conseqüentemente, elevar a barreira total da reação. Estes intermediários são evitados nas reações enzimáticas ${ }^{5}$.

A transferência também pode neutralizar ou alterar a carga dos grupos reagentes, facilitando outras etapas do mecanismo de reação. Por exemplo, o ataque nucleofílico das PTPs sobre o substrato é facilitado pela doação de $\mathrm{H}^{+}$ao grupo de saída. Caso esta transferência de $\mathrm{H}^{+}$não aconteça (após uma mutação do resíduo que funciona como ácido geral), outras etapas do mecanismo de reação são energeticamente desestabilizadas ou até impedidas ${ }^{15,38}$.

Avaliar a contribuição da catálise ácido-base geral para a diminuição da barreira de reação não é trivial, porque a transferência de $\mathrm{H}^{+}$pode influenciar diferentes etapas ou ocorrer em etapas não limitantes. Em solução aquosa, a catálise ácido-base geral propicia aumentos na constante de velocidade de cerca de $10^{2}-10^{3}$ vezes $^{5}$. Para as PTPs, cerca de $5 \mathrm{kcal} / \mathrm{mol}$ de estabilização do TS são atribuídos à catálise ácido-base geral, tanto por simulações computacionais ${ }^{15}$ como por mutações do resíduo envolvido na transferência de $\mathrm{H}^{+39}$.

\section{Interação eletrostática}

A importância das interações eletrostáticas foi rapidamente identificada para a ligação de substratos e para estabilidade e enovelamento de proteínas, através da formação de pares iônicos ou pontes salinas ${ }^{5}$. Porém, sua importância como mecanismo catalítico não foi comprovada até o advento de experimentos de mutação sítio-dirigida e de simulações computacionais ${ }^{26,40}$.

Mutações em resíduos que estabilizam cargas formais ou parciais do TS resultam em diminuição de $k_{\text {cat }}{ }^{41}$. Alterações no microambiente dielétrico de uma reação podem diminuir a altura da barreira em mais de $20 \mathrm{kcal} / \mathrm{mol}^{42}$. Assim, enzimas fornecem um microambiente altamente polar cujo potencial eletrostático complementa as mudanças de cargas observadas ao longo de uma reação ${ }^{18}$ (Figura 5).

A coordenação (não covalente) com íons metálicos e ligações de hidrogênio são normalmente consideradas interações eletrostáticas, pois são modeladas com razoável sucesso por esta força $a^{18,23}$.

Simulações computacionais mostram repetidamente $e^{8,21,23,24}$ que a interação eletrostática entre o ambiente enzimático e o TS das reações catalisadas é a maior responsável pela diminuição de $\Delta \mathrm{G}_{\mathrm{enz}}^{\dot{p}}$ em relação a $\Delta \mathrm{G}_{\text {sol }}^{\ddagger}$ (Figura 2). Mesmo nos casos onde o TS é menos polar que o estado reagente, a estabilização eletrostática do TS na enzima é maior que em solução $0^{20}$. O aumento médio de velocidade atribuído à interação eletrostática é calculado em $10^{11}$ vezes (equivalente a um abaixamento de $17 \mathrm{kcal} / \mathrm{mol}$ na energia de ativação) $)^{8}$.

Solventes polares, como a água, podem reorientar seus dipolos para estabilizar a distribuição de carga atingida no TS. Em uma enzima, no entanto, os dipolos que estabilizam o TS já estão préorientados no complexo E.S para estabilizar as cargas do TS. Em solução, a energia para reorientar os dipolos do solvente complementariamente às cargas do TS é elevada. Na enzima, a energia de orientação dos dipolos no sítio ativo já foi gasta durante o enovelamento e a formação da estrutura nativa. Portanto, enzimas são "supersolventes", que funcionam por substituição de solvatação do TS, com pequena energia de reorganização ${ }^{18}$.

Uma proposta relacionada, em que enzimas propiciariam microambientes apolares que desestabilizam os reagentes por dessolvataçã $0^{5,28}$ (vide supra), é baseada na observação que algumas reações em fase gasosa ou em solventes apolares ocorrem mais rapidamente que as mesmas reações em soluções polares ${ }^{42}$. Energias de

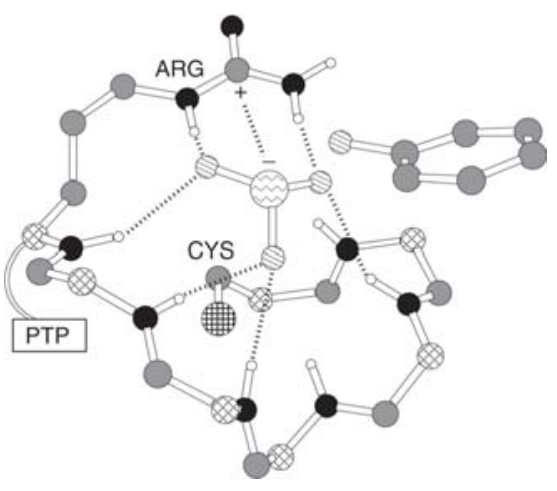

Figura 5. Exemplo de estabilização eletrostática do TS: estrutura do sítio ativo coordenado ao TS da primeira etapa de reação catalisada pelas PTPs (Figura 1). Interações eletrostáticas entre o grupo fosfato $\left(\mathrm{PO}_{3}^{-}\right)$e a carga positiva da arginina $(A R G)$ e as ligações de hidrogênio estão indicadas por linhas tracejadas. A estrutura foi obtida a partir de uma simulação de dinâmica molecular $^{15}$ e parte dos átomos foram apagados para facilitar a visualização. Legenda para os tipos atômicos: $H$ (branco), C(cinza), $C_{\alpha}$ (linhas diagonais cruzadas), N(preto), O(linhas diagonais), P(ondulado) e S(linhas cruzadas)

solvatação do reagente por água e pelo sítio enzimático (solvatação assume um sentido generalizado aqui) podem ser calculadas em comparação com a reação em fase gasosa, ou seja, na ausência de qualquer solvente. Por exemplo, a energia de solvatação calculada para o estado reagente na enzima haloalcano desalogenase é cerca de 30 $\mathrm{kcal} / \mathrm{mol}$ menor que em solução aquosa e, portanto, supôs-se que a enzima desestabilizaria o substrato ao diminuir sua solvatação ${ }^{28}$. Entretanto, a energia de pré-organização do sítio ativo é incorretamente descartada neste cálculo (ao contrário da reorganização do solvente aquoso $)^{9}$. A hipótese de dessolvatação também é refutada se um ciclo termodinâmico (como a Equação 5) inclui a transferência dos fragmentos reativos polares do solvente aquoso (referência) para o possível microambiente apolar. Esta transferência envolve uma alta energia, que não está disponível no processo de catálise ${ }^{18}$. Sítios ativos são ambientes altamente polares e heterogêneos, bastante diferentes de solventes apolares ou da fase gasosa.

\section{Efeitos entrópicos}

O aumento da velocidade de reações por efeitos entrópicos é freqüentemente considerado um importante mecanismo catalítico ${ }^{5,24,43}$. Esta proposta já foi enunciada de diversas maneiras, mas em essência implica que o espaço configuracional disponível para os reagentes em solução é restringido no sítio ativo enzimático, resultando em significativas diferenças entrópicas entre as energias livres de ativação na enzima e na reação de referência em solução.

A definição do estado de referência em solução é crucial para correta estimativa dos efeitos entrópicos. O efeito de concentração em solução aquosa, referente à aproximação dos reagentes, é dado por $\approx-R T \ln 55$ para cada par de reagentes. Assim para uma reação bimolecular $\mathrm{R}+\mathrm{S}$ em solução (Figura 2$)$, esta contribuição $\left(\Delta \mathrm{G}_{\text {comp }}\right)$ é $2.4 \mathrm{kcal} / \mathrm{mol}$ a $300 \mathrm{~K}$. Descontado o efeito de concentração, a diferença entre as barreiras entrópicas $(\Delta S)$ para ativação da reação em solução e na enzima pode ser escrita por:

$\left(\Delta \Delta \mathrm{S}^{*}\right)$

$$
\begin{aligned}
& =\left[\Delta \mathrm{S}_{\text {enz }}^{\ddagger}-\Delta \mathrm{S}_{\text {sol }}^{\ddagger}\right] \\
& =\left[\left(S^{\mathrm{TS}}{ }_{\text {enz }}-\mathrm{S}^{\mathrm{E} . \mathrm{S}_{\text {enz }}}\right)-\left(\mathrm{S}_{\text {sol }}^{\mathrm{TS}}-\mathrm{S}_{\text {sol }}^{\mathrm{R} . \mathrm{S}}\right)\right] \\
& =\left[\left(\mathrm{S}^{\mathrm{TS}}{ }_{\text {enz }}^{\mathrm{enz}}-\mathrm{S}^{\mathrm{TS}}{ }_{\text {sol }}{ }^{\mathrm{enz}}\right)-\Delta \mathrm{S}_{B}\right]
\end{aligned}
$$

onde $\Delta \mathrm{S}_{B}=\mathrm{S}_{\text {enz }}^{\mathrm{ES}}-\mathrm{S}^{\mathrm{R} . \mathrm{S}}$ sol é a entropia de ligação do substrato, considerando os estados E.S e R.S (Figura 2). 
As propostas que sustentam o efeito entrópico como mecanismo catalítico assumem implicitamente que os graus de liberdade do TS em solução e na enzima estão congelados, ou seja $\mathrm{S}_{\text {enz }}^{\mathrm{TS}}=\mathrm{S}_{\text {sol }}^{\mathrm{TS}} \approx 0 \mathrm{e}$, portanto, superestimam $\left(\Delta \Delta S^{\ddagger}\right)_{\text {sol } \rightarrow \text { enz }}=-\Delta S_{B}{ }^{19,24,41}$. Esta suposição é baseada num raciocínio para reações bimoleculares utilizando reagentes esféricos ${ }^{5}$ em que até -35 unidades entrópicas (cerca de 10 $\mathrm{kcal} / \mathrm{mol}$ a $300 \mathrm{~K}$ ) seriam obtidas pela restrição translacional no sítio ativo. Porém, este raciocínio não é válido para estruturas moleculares, porque parte da movimentação livre nos complexos R.S e E.S também está livre no TS (parte dos graus de liberdade translacionais e rotacionais tidos como "congelados" são, na verdade, transformados em vibrações de baixa frequiência dos TS, cuja contribuição entrópica é bastante apreciável) $)^{18,41,44}$.

Simulações computacionais das contribuições entrópicas ainda sofrem de problemas de convergência e, portanto, as estimativas não são totalmente seguras ${ }^{45}$, mas simulações semiquantitativas $^{18,45}$ indicam que $\left(\Delta \Delta \mathrm{S}^{\dagger}\right)_{\text {sol } \rightarrow \text { enz }}<1 \mathrm{kcal} / \mathrm{mol}$.

Nenhum experimento demonstrou diretamente que a catálise enzimática estivesse associada à $\left(\Delta \Delta \mathrm{S}^{\ddagger}\right)_{\text {sol } \rightarrow \text { enz }}$. A análise das contribuições para energia livre de reações enzimáticas e de sua referência em solução determinadas por gráficos de Arrhenius ${ }^{10,45}$ indica que a contribuição entrópica é equivalente nos dois ambientes. Dados experimentais obtidos em solução ${ }^{46}$ sugerem que a água já impõe restrições à movimentação translacional e rotacional de solutos polares e, portanto, o ganho em termos destas contribuições pela transferência dos reagentes para o sítio ativo enzimático seria pequeno.

Os aumentos de velocidade observados em reações intramoleculares (ver seção Espécie catalisada), em que os reagentes estão covalentemente ligados e parcialmente imobilizados, são citados como evidência de catálise por efeitos entrópicos. Porém, a informação obtida destes modelos não é diretamente transferível para reações enzimáticas, porque a restrição das configurações disponíveis na reação intramolecular não está necessariamente ligada às possíveis restrições observadas no sítio ativo, em comparação com a reação intermolecular de referência em solução ${ }^{18}$. Simulações computacionais também indicam que o aumento da velocidade de reações intramoleculares não está necessariamente associado a contribuições entrópicas ${ }^{29}$.

Portanto, embora efeitos entrópicos para catálise não possam ser totalmente ignorados, a magnitude destas contribuições é menor que o tradicionalmente proposto ${ }^{5}$.

\section{Tensão e impedimento estérico}

A tensão ou impedimento estérico resultante da aproximação espacial entre moléculas ou partes da mesma molécula foram sugeridos como um possível mecanismo catalítico ligado à desestabilização do substrato (ver seção Espécie catalisada) ${ }^{5}$.

Existem dois casos limites nessa hipótese. Se o sítio ativo for relativamente rígido e sua estrutura complementar ao TS, o reagente sofreria uma distorção geométrica para se acomodar no sítio ati$\mathrm{vo}^{5}$, diminuindo a energia de ativação como mostrado no perfil B, Figura 3. Caso o sítio ativo seja flexível e o substrato rígido, a formação do complexo E.S seria acompanhada por uma mudança conformacional na enzima que tensionaria e desestabilizaria a geometria do substrato, aumentando a energia livre do sistema (perfil D, Figura 3$)^{5}$.

Nenhuma observação experimental suporta diretamente ambas as propostas $^{5}$ e as evidências existentes são consideradas ambíguas ${ }^{12}$. A catálise na lisozima é tradicionalmente citada como evidência da tensão que pode ser exercida sobre o substrato, pois a estrutura do sítio ativo parece complementar à conformação "barco" do substrato (um sacarídeo, cuja conformação "cadeira" é cerca de $5 \mathrm{kcal} / \mathrm{mol}$ mais estável em solução aquosa). No entanto, a diferença de energia livre associada à mudança da conformação cadeira para conformação sofá entre a solução aquosa e o ambiente enzimático é menor que $1 \mathrm{kcal} / \mathrm{mol}^{18}$. Portanto, esta diferença não é suficiente para explicar o abaixamento da energia de ativação no ambiente enzimático.

Medidas de RMN e simulações computacionais mostram que enzimas são moléculas bastante flexíveis, que podem acomodar mudanças na estrutura do substrato sem aumento significativo da energia livre ${ }^{8,37}$. Mudanças geométricas do reagente associadas à formação do TS são menores que $1 \AA$, e deformações desta magnitude são facilmente acomodadas pelos modos vibracionais de baixa energia da proteína (que, pictoricamente, pode ser comparada a um conjunto de molas com baixa constante de força $)^{18}$.

Numa simulação computacional, o impedimento estérico pode ser definido como o potencial repulsivo das interações de van der Waals e as contribuições da distorção de ligações, ângulos e diedrais. A contribuição total destas interações para diminuição de $\Delta \mathrm{G}_{\mathrm{enz}}^{*}$ foi

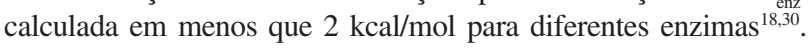

A proposta de "ajuste induzido"5 é semelhante mas não está relacionada à catálise, porque a energia de ligação é utilizada na modificação da estrutura enzimática para regular a especificidade pelo substrato, ao invés de diminuir $\Delta \mathrm{G}_{\text {enz }}^{\ddagger}$.

\section{Efeitos quânticos e dinâmicos}

A dinâmica enzimática também foi proposta recentemente como um possível mecanismo catalítico ${ }^{2,8}$.

Movimentações de larga escala na estrutura enzimática como torção de sub-unidades, modos vibracionais de baixa freqüência e reposicionamento de grupos protéicos causados, por exemplo, pela ligação do substrato ou de um regulador alostérico, são alterações conformacionais na enzima responsáveis pelo correto posicionamento dos grupos catalíticos. Se a amostragem conformacional é feita corretamente durante as simulações computacionais, estes efeitos, chamados de reorganização da estrutura enzimática ${ }^{23}$, são incorporados normalmente ${ }^{18,21,24}$ e não representam um mecanismo catalítico em particular ${ }^{8,41}$.

A liberdade conformacional não deve ser confundida com as flutuações dinâmicas da estrutura protéica, principalmente as vibrações que amplificam efeitos quânticos como tunelamento ${ }^{47,48}$. A teoria generalizada do estado de transição ${ }^{3,49}$ pode ser usada para racionalizar estes efeitos. Segundo a Equação:

$$
k(T)=\tau(T)\left(k_{B} T / h\right) \exp \left[-\Delta \mathrm{G}^{\ddagger} / R T\right]
$$

onde $R, h$ e $\mathrm{k}_{\mathrm{B}}$ são constantes, e $T$ é a temperatura, a constante de velocidade da reação, $k(T)$, pode ser elevada pelo aumento do coeficiente de transmissão, $\tau(T)$, ou pela diminuição da barreira de reação, $\Delta \mathrm{G}^{\ddagger}$.

As mudanças conformacionais descritas acima alteram apenas $\Delta \mathrm{G}^{\ddagger}$. Já o fator de transmissão pode ser alterado pela dinâmica do sistema reativo, onde $\tau(T) \leq 1$, ou seja, uma trajetória de reação pode ultrapassar o TS, mas ser improdutiva e retornar aos reagentes.

Além de um recruzamento não-reativo clássico, $\tau(T)$ pode ser alterado por efeitos de solvatação de não-equilíbrio (por exemplo, proveniente de uma distribuição configuracional dos reagentes fora do equilíbrio) e por efeitos quânticos como tunelamento to $^{2,841,43,50}$. Os efeitos de recruzamento e de não-equilíbrio podem apenas tor$\operatorname{nar} \tau(T)$ menor que um e, usualmente, já são pequenos em solução aquosa. Neste meio, $\tau(T)$ é quase unitário ${ }^{2}$. Assim, pouca ou nenhuma vantagem catalítica pode ser explorada por enzimas buscando minimizar estes efeitos, de acordo com resultados observados em simulações computacionais ${ }^{2,8}$. 
Já o tunelamento pode fenomenologicamente resultar em $\tau(T)>1$, ou seja, pode amplificar a constante de velocidade sem alterar o termo exponencial na Equação 7. Contribuições de até 3 ordens de magnitude para o aumento da velocidade de reações enzimáticas foram atribuídas à dinâmica da proteína, ou seja, às vibrações que amplificam o tunelamento em comparação com a reação em solução, nos sistemas em que uma transferência de hidrogênio (tanto nas formas $\mathrm{H}^{+}, \mathrm{H}$ neutro e $\mathrm{H}^{-}$) é determinante da velocidade de reação $0^{8,43,50}$. As desidrogenases de álcool ${ }^{47}$ e de lactato $^{48}$ são exemplos de sistemas em que este mecanismo catalítico é observado.

\section{CONCLUSÃO}

Diversas teorias e hipóteses já foram propostas para explicar porque enzimas são catalisadores de extrema eficiência. Neste texto apresentamos uma perspectiva computacional destas propostas, principalmente daquelas que foram testadas quantitativamente e comparadas com experimentos.

A utilização de ciclos termodinâmicos e de corretas reações de referência é essencial para racionalização das interações e dos mecanismos catalíticos. Sem dúvida, cada enzima utiliza uma combinação das forças e interações revisadas aqui, dependendo da reação química catalisada. Contudo, a espécie que sofre influência determinante do ambiente enzimático é o estado de transição. Este é estabilizado principalmente por interações eletrostáticas geradas pelo sítio ativo e pela estrutura enzimática pré-organizados. Em média, reduções de cerca de $17 \mathrm{kcal} / \mathrm{mol}$ na energia de ativação podem ser obtidas por este mecanismo catalítico.

O aumento da fração molar de conformações próxima ao ataque (NACs) e a desestabilização do substrato contribuem em escala bem menor (no máximo $5 \mathrm{kcal} / \mathrm{mol}$ ) para reduções na energia de ativação enzimática. A desestabilização é viável principalmente pelo modelo do sítio dividido. A catálise covalente, a catálise ácido-base geral e efeitos quânticos e dinâmicos também podem contribuir na mesma magnitude $(5 \mathrm{kcal} / \mathrm{mol} \mathrm{cada})$ para o aumento da velocidade das reações enzimáticas em que intermediários são formados ou hidrogênio seja transferido, respectivamente.

Já efeitos entrópicos e impedimento estérico, antes postulados como importantes mecanismos catalíticos, contribuem, na verdade, com menos que $3 \mathrm{kcal} / \mathrm{mol}$ para reduções na energia de ativação enzimática e têm pouca influência sobre os aumentos de velocidade observados.

Simulações computacionais são, portanto, ferramentas bastante poderosas na investigação da atividade enzimática e na elucidação do poder catalítico destas macromoléculas biológicas.

\section{AGRADECIMENTOS}

$\mathrm{O}$ autor gostaria de agradecer as bolsas financiadas pela FAPESP (Fundação de Amparo à Pesquisa do Estado de São Paulo), nos projetos 99/07688-9 e 2005/03995-7.

\section{REFERÊNCIAS}

1. Lad, C.; Williams, N. H.; Wolfenden, R.; Proc. Natl. Acad. Sci. U.S.A. 2003 $100,5607$.

2. Benkovic, S. J.; Hammes-Schiffer, S.; Science 2003, 301, 1196.

3. Billing, G. D.; Mikkelsen, V.; Introduction to Molecular Dynamics and Chemical Kinetics, Wiley: New York, $1^{\text {st }}$ ed., 1996.

4. Pauling, L.; Nature 1948, 161, 707.

5. Jencks, W. P.; Catalysis in Chemistry and Enzymology, Dover: New York, $1^{\text {st }}$ ed., 1987.

6. Menger, F. M.; Biochemistry 1992, 31, 5368.

7. Bruice, T. C.; Chem. Rev. 2006, 106, 3119.

8. Garcia-Viloca, M.; Gao, J.; Karplus, M.; Truhlar, D. G.; Science 2004, 303, 186.

9. Warshel, A.; Sharma, P. K.; Kato, M.; Xiang, Y.; Liu, H.; Olsson, M. H. M.; Chem. Rev. 2006, 106, 3210.

10. Bruice, T. C.; Acc. Chem. Res. 2002, 35, 139.

11. Arantes, G. M.; Tese de Doutorado, Unversidade de São Paulo, Brasil, 2004.

12. Fersht, A.; Structure and Mechanism in Protein Science: A Guide to Enzyme Catalysis and Protein Folding, W. H. Freeman: New York, $1^{\text {st }}$ ed., 1999.

13. Voet, D.; Voet, J.; Biochemistry, Wiley: New York, $2^{\text {nd }}$ ed., 1995.

14. Raushel, F. M.; Thoden, J. B.; Holden, H. M.; Acc. Chem. Res. 2003, 36 , 539.

15. Arantes, G. M.; Biochem. J. 2006, 399, 343.

16. Arantes, G. M.; Chaimovich, H.; J. Phys. Chem. A 2005, 109, 5625

17. Warshel, A.; Florián, J.; Proc. Natl. Acad. Sci. U.S.A. 1998, 95, 5950.

18. Warshel, A.; Computer Modeling of Chemical Reactions in Enzymes and Solutions, Wiley: New York, $1^{\text {st }}$ ed., 1991.

19. Kollman, P. A.; Kuhn, B.; Donini, O.; Perakyla, M.; Stanton, R.; Bakowies, D.; Acc. Chem. Res. 2001, 34, 72.

20. Roca, M.; Martí, S.; Andrés, J.; Moliner, V.; Tunón, I.; Bertrán, J.; Williams, I. H.; J. Am. Chem. Soc. 2003, 125, 7726.

21. Field, M. J.; J. Comp. Chem. 2002, 23, 48.

22. Dwyer, M. A.; Looger, L. L.; Hellinga, H. W.; Science 2004, 304, 1967.

23. Kollman, P. A.; Kuhn, B.; Perakyla, M.; J. Phys. Chem. B 2002, 106, 1537.

24. Åqvist, J.; Warshel, A.; Chem. Rev. 1993, 93, 2523.

25. Menger, F. M.; Acc. Chem. Res. 1985, 18, 128.

26. Leatherbarrow, R. J.; Fersht, A. R.; Winter, G.; Proc. Natl. Acad. Sci. U.S.A. 1985, 82, 7840.

27. Warshel, A.; J. Biol. Chem. 1998, 273, 27035.

28. Gao, J.; Ma, S.; Major, D. T.; Nam, K.; Pu, J.; Truhlar, D. G.; Chem. Rev. 2006, 106, 3188.

29. Bruice, T. C.; Lightstone, F. C.; Acc. Chem. Res. 1999, 32, 127.

30. Shurki, A.; Strajbl, M.; Villá, J.; Warshel, A.; J. Am. Chem. Soc 2002, 124, 4097.

31. Albery, W. J.; Knowles, J. R.; Biochemistry 1976, 15, 5631.

32. Rudolph, J.; Biochemistry 2002, 41, 14613.

33. Kraut, D. A.; Carroll, K. S.; Herschlag, D.; Annu. Rev. Biochem. 2003, 72, 517.

34. Gregersen, B. A.; Lopez, X.; York, D. M.; J. Am. Chem. Soc. 2003, 125, 7178

35. Thain, E. M.; J. Chem. Soc. 1957, 4694.

36. Zhang, X.; Houk, K. N.; Acc. Chem. Res. 2005, 38, 379.

37. Hammes, G. G.; Biochemistry 2002, 41, 8221.

38. Arantes, G. M.; Loos, M.; Phys. Chem. Chem. Phys. 2006, 8, 347.

39. Jackson, M. D.; Denu, J. M.; Chem. Rev 2001, 101, 2313.

40. Gilson, M. K.; Honig, B. H.; Nature 1987, 330, 84.

41. Villà, J.; Warshel, A.; J. Phys. Chem. B 2001, 105, 7887.

42. Menegon, G.; Loos, M.; Chaimovich, H.; J. Phys. Chem. A 2002, 106, 9078.

43. Kohen, A.; Klinman, J. P.; Acc. Chem. Res. 1998, 31, 397.

44. Ayala, P.; Schlegel, H. B.; J. Chem. Phys. 1998, 108, 2314.

45. Villá, J.; Strajbl, M.; Glennon, T. M.; Sham, Y. Y.; Chu, Z. T.; Warshel, A.; Proc. Natl. Acad. Sci. U.S.A. 2000, 97, 11899.

46. Yu, Y. B.; J. Phys. Chem. B 2003, 107, 1721.

47. Nagel, Z. D.; Klinman, J. P.; Chem. Rev. 2006, 106, 3095.

48. Antoniou, D.; Basner, J.; Nunez, S.; Schwartz, S. D.; Chem. Rev. 2006 106, 3170 .

49. Truhlar, D. G.; Garrett, B. C.; Klippenstein, S. J.; J. Phys. Chem. 1996 100, 12771 .

50. Bala, P.; Grochowski, P.; Nowinski, K.; Lesyng, B.; McCammon, J. A.; Biophys. J. 2000, 79, 1253. 